\title{
Worldwide clustering of surgical indicators and predictors of risk of catastrophic expenditure for surgical care
}

\author{
Songul Cinaroglu*, Onur Baser ${ }^{2,3,4}$
}

'Department of Health Care Management, Faculty of Economics and Administrative Sciences, Hacettepe University, Ankara, Turkey, ${ }^{2}$ STATinMED Research, New York, USA, ${ }^{3}$ Columbia University, Center for Innovation and Outcomes Research, Department of Surgery, New York, USA, ${ }^{4}$ Department of Economics, MEF University, Istanbul, Turkey

\begin{abstract}
Introduction: Better access to surgical care is crucial to improve general health status of the population. Despite studies indicate cross-country differences according to the general health indicators, there is a scarcity of knowledge about the differences between countries according to the surgical indicators. This study aims to classify countries according to the surgical care indicators and to identify predictors of risk of catastrophic health expenditure for surgical care.
\end{abstract}

Methods: Data came from the World Health Organization and World Bank statistics and a total of 177 countries were selected for this study. Variable groups are determined as follows: Total density of medical imaging technologies, workforce distribution in surgical care, number of surgical procedures, and risk of catastrophic expenditure for surgical care. K-means clustering algorithm was used to classify countries according to the surgical indicators. Optimal number of clusters was determined using within cluster sum of squares and scree plot. Silhouette index was used to examine clustering performance. Random Forest decision tree approach was used to determine the predictors of the risk for catastrophic expenditure for surgical care.

Results: The study results show that there are four country groups exists according to their surgical care indicators. High- and low-income countries are in different clusters. The third cluster which consists of low-income countries has high Silhouette index value (0.75). Surgeon density and density of the medical imaging technologies are determinators of the risk for catastrophic expenditure for surgical care (area under the receiver operating characteristic curve $=0.82$ ).

Conclusions: The study results pose that there is a need for more effective health plans to overcome the differences between countries in terms of surgical care indicators. Determining strategies about distribution of surgical workforce and medical imaging technologies considering accessibility and equality are recommended for health policymakers.

Keywords: Surgical care; catastrophic expenditure; clustering; decision tree

\footnotetext{
*Corresponding author: Songul Cinaroglu, Department of Health Care Management, Faculty of Economics and Administrative Sciences, Hacettepe University, 06800 Beytepe Ankara, Turkey. E-mail: cinaroglus@hacettepe.edu.tr
} 


\section{INTRODUCTION}

Surgery is a fundamental part of basic health-care services (1). Access to surgery is an important component of good functioning of health system for all countries at different levels development (2). Increasing access to surgical services will play a central role to improve public health. However, most of the world's population does not access to surgical care and this represents a crisis for low- and middle-income countries (3).

In surgery, a significant portion of the total costs is associated with consumable supplies (4). Medical imaging technologies which are including computed tomography (CT), magnetic resonance (MR), positron emission tomography, linear accelerator (LINAC), and the robotic platform provide significant health and cost benefits to improve health for all $(5,6)$. Robotic surgery is one of the other surgical systems which has been used rapidly in general surgery. It has been reported that high cost health-care expenditures that are usually associated with open heart surgery, certain cancers, critically ill infants, and major trauma result from automobile accident (7). Surgery accesses a tremendous volume worldwide. This increasing worldwide growth shows a great need for public-health efforts to improve the monitoring, safety, and availability of surgical services, especially in view of their high risk and expense (2). From the other point of view, lack of appropriate training and poor coordination of service delivery are major problems of surgery. A public health strategy for surgical care is essential and understanding the relationships between surgery and public health is necessary to improve public health outcomes. Literature suggests that high density of surgeons is associated with significant reductions in deaths (8). Unfortunately, population analysis points out a future critical shortage of general surgeons $(9,10)$. To fight against surgeon shortage, developed countries encourage surgeon volunteerism (10). In these circumstances, the lack of data on the recommended measures to evaluate national surgical services is a disturbing reality worldwide. As many as $70 \%$ of countries have no information on the number of surgeries performed, and virtually none of them attempts to assess the distribution of surgical resources or results. This deficit, however, is not limited to countries with poor and low total expenditure on health per capita. Some countries of medium total expenditure on health per capita, such as Peru, also lack this information (11).

On the other hand, the global volume of major surgery increased substantially in recent years and health system differences have a large impact on rates of surgery (12). Expenditures for access to better health care consist big part of catastrophic health expenditure because individuals face with catastrophic health expenditures to finance their surgical care. Shrime et al. (2015) (2) state that approximately 150 million individuals worldwide face catastrophic expenditure each year from medical costs alone, and the non-medical costs of accessing care increase that number. Xu et al. (2003) (13) state that the level of catastrophic health expenditure is high in low- and middle-income countries which are experiencing health transformation process. Moreover, the risk of catastrophic expenditure increased, more in the richer than in the poorer quintiles (2). Shrime et al. (2015) (2) postulated that a large proportion of worldwide financial catastrophe caused by medical care would be attributable to surgery and this burden would fall most heavily on the poor. These results highlight that policymakers need to be aware of the differences between countries according to the surgical indicators and to determine policies to protect households from devastating effects of catastrophic surgical expenditure.

Using data on geographic variations in care and expenditure may help policymakers to develop strategies for reducing surgical rates and the level of expenditures for surgical care. Furthermore, these strategies will ensure greater benefits in preventing adverse events while improving technical quality of surgical care (14). To date, despite global health authorities emphasize cross-country differences according to surgical care, there has been no published study on grouping of countries according to the surgical care indicators and predictors of catastrophic expenditure for surgical care. To fill this void in the literature, this study aims grouping of countries according to the surgical care indicators and to find predictors of the risk of catastrophic expenditure for surgical care. 


\section{METHODS}

\section{Dataset}

In this study, data came from World Health Organization (WHO) $(15,16)$ and World Bank (17) and a total of 177 WHO countries were selected for this study. Table 1 presents detailed explanation about variable groups, data sources, and explanations of study variables.

\section{Analysis method}

In this study, as the data came from several sources, they differed in their measurement units. Before performing cluster analysis, $\mathrm{Z}$ transformation was performed to bring the coefficients zero-one range (18). $\mathrm{K}$-means clustering was performed to classify countries according to surgical care indicators. This is one of the most popular clustering algorithms that minimizes the clustering error (19). This algorithm aims to separate " $n$ " observations into " $k$ " clusters in which each observation belongs to the cluster within the nearest mean (20). K-means algorithm calculates its centers iteratively (21). In this study, before performing cluster analysis, optimal number of clusters determined using within cluster sums of squares and presented on a scree plot. After that, Silhouette clustering performance index is used to determine the optimal number of clusters which works well with k-means clustering (22). High Silhouette value (near to 1 ) is considered well clustered, and objects with a low value may be outliers. To determine predictors of catastrophic expenditure for surgical care, decision tree approach was used. For this aim, continuous catastrophic expenditure risk for surgical care (\% of people at risk) dichotomized using median values as cutoff points. Next, Random Forest algorithm was used for generating the decision tree. Random Forest developed offers an alternative approach for increasing predictive accuracy (23). It uses Classification and Regression Tree (CART) to generate trees (24). CART is a non-parametric model to choose the most important subset variables that determine the outcome. It uses binary recursive partitioning to split data instances into homogenous subsets using Gini index measure (25). Random Forest classification model refers to categorical dependent variable, but if the response is continuous the Random Forest performs regression (24).

\section{RESULTS}

\section{Descriptive statistics}

Summary statistics are reported in Table 2. The median scores of surgical care indicators belong to 177 members of the WHO as follows: MRI

TABLE 1. Study variables

\begin{tabular}{|c|c|c|}
\hline Variable group & Resource & Variable \\
\hline \multirow[t]{5}{*}{ Medical technology } & WHO* & MRI density per million population \\
\hline & & $\mathrm{CT}$ density per million population \\
\hline & & LINAC density per million population \\
\hline & & Telecobalt unit density per million population \\
\hline & & Radiotherapy density per million population \\
\hline \multirow[t]{3}{*}{ Number of surgeon } & WHO** & Surgeon density per million population \\
\hline & & Anesthesiologist density per million population \\
\hline & & Obstetrician density per million population \\
\hline Number of surgical procedures & $W B^{* * *}$ & Number of surgical procedures per million population \\
\hline $\begin{array}{l}\text { Catastrophic health expenditure for surgical } \\
\text { care }\end{array}$ & $W^{* \star *}$ & Catastrophic expenditure risk for surgical care (\% of people at risk) \\
\hline
\end{tabular}

${ }^{*}$ WHO. WHO Global Health Observatory Data Repository. Geneva: WHO. Available from: http://www.apps.who.int/gho/data/node. main.MEDICALDEVICES?lang=en. [Last accessed on 2016 Sep 26].

**WHO. WHO The Lancet Global Health, Study Results to Build Global Surgical Specialist Workforce Database by Country. Geneva: WHO; 2015. Holmer H, Lantz A, Kunjumen T, Finlayson S, Hoyler M, Siyam A, et al. Global distribution of surgeons, anesthesiologists, and obstetricians. Lancet Glob Health 2015;3 Suppl 2:S9-11.

${ }^{* * * W B}$ The World Bank World Development Indicators. Available from: http://www.data.worldbank.org/indicator. [Last accessed on 2016 Sep 20].

WHO: World Health Organization, WB: World Bank, MRI: Magnetic resonance imaging, CT: Computed tomography, LINAC: Linear accelerator 
density per million population (median 1.20; minimum 0.04; maximum 132.17), CT density per million population (median 4.18; minimum 0.07; maximum 194.10), LINAC density per million population (median 0.34; minimum 0.01; maximum 26.43), telecobalt unit density per million population (median 0.12; minimum. 0.02; maximum 10.12), radiotherapy density per million population (median 0.64; minimum 0.01; maximum 30.64), surgeon density per million population (median 6.70; minimum 0.08; maximum 138), anesthesiologist density per million population (median 2.80; minimum 0.01; maximum 65), obstetrician density per million population (median 6.01; minimum 0.04; maximum 140.67), number of surgical procedures per million population (median 4267; minimum 53; maximum 30537), and catastrophic expenditure risk for surgical care (\% of people at risk) (median 31.20; minimum 0.10; maximum 92.80).

\section{Clustering of countries according to the surgical care indicators}

Determining optimal number of clusters

Optimal number of country clusters according to the surgical care indicators was determined using within cluster sum of squares, and the results are presented on scree plot (Figure 1). In this figure, the location of the elbow in the resulting plot suggests a suitable number of clusters for the k-means. For this study, we might conclude that there are four clusters.

\section{K-means cluster analysis results}

$\mathrm{K}$-means cluster analysis results are visualized in Figure 2. Countries which are representing observations of this study are presented by points in Figure 2. Different colors and ellipse are drawn around each cluster. Cluster plot indicates four groups, and most of them are developed countries (United States, United Kingdom, Norway, Germany, etc.) which are in the first cluster which are represented with red color. Moreover, low (Ethiopia, Guatemala, Kenya, Madagascar, etc.) and middle-income (Brazil, Turkey, Hungary, Thailand, etc.) countries which are represented in blue and purple colors are in the third and fourth clusters, respectively. Silhouette value shows that cluster performances of third (0.75) and fourth (0.45) clusters which are representing low- and middle-income countries outperform compared with other clusters.

\section{Binary coding of catastrophic expenditure for surgical care}

One of the aims of this study is to find predictors of the risk of catastrophic expenditure for surgical care using decision tree approach. For this aim, catastrophic expenditure risk for surgical care (\% of people at risk) dichotomized using median values as cutoff points, and they recoded as 0 and 1 . It is seen that after recoding, the number of observations for both of two binary variable groups are balanced (1: 49.7\%; 0:50.3\%), which is essential to improve the performance of decision trees. Table 3 presents cutoff points and binary coding for the variable of catastrophic expenditure for surgical care.

TABLE 2. Descriptive statistics

\begin{tabular}{lcccc}
\hline Variables & $\mathrm{N}$ & Median & Min. & Max. \\
\hline MRI density per million population & 177 & 1.20 & 0.04 & 132.17 \\
CT density per million population & 177 & 4.18 & 0.07 & 194.10 \\
LINAC density per million population & 177 & 0.34 & 0.01 & 26.43 \\
Telecobalt unit density per million population & 177 & 0.12 & 0.02 & 10.12 \\
Radiotherapy density per million population & 177 & 0.64 & 0.01 & 30.64 \\
Surgeon density per million population & 177 & 6.70 & 0.08 & 138 \\
Anesthesiologist density per million population & 177 & 2.80 & 0.01 & 65 \\
Obstetrician density & 177 & 6.01 & 0.04 & 140.67 \\
Number of surgical procedures per million population & 177 & 4267 & 53 & 30537 \\
Catastrophic expenditure risk for surgical care (\% of people at risk) & 177 & 31.20 & 0.10 & 92.80 \\
\hline
\end{tabular}

MRI: Magnetic resonance imaging, CT: Computed tomography, LINAC: Linear accelerator 
TABLE 3. Cutoff Points and binary coding for catastrophic expenditure for surgical care

\begin{tabular}{lcclcc}
\hline Variable & $\mathrm{N}$ & Median & Cutoff points & $\mathrm{n}(\%)$ & Recoded As \\
\hline $\begin{array}{l}\text { Catastrophic expenditure for surgical care } \\
\text { (cata surg care) }\end{array}$ & 177 & 31.20 & cata surg care $\geq 31.20$ & $88(49.7)$ & 1 \\
& & & & & \\
& & & cata surg care $<31.20$ & $89(50.3)$ & 0 \\
\hline
\end{tabular}

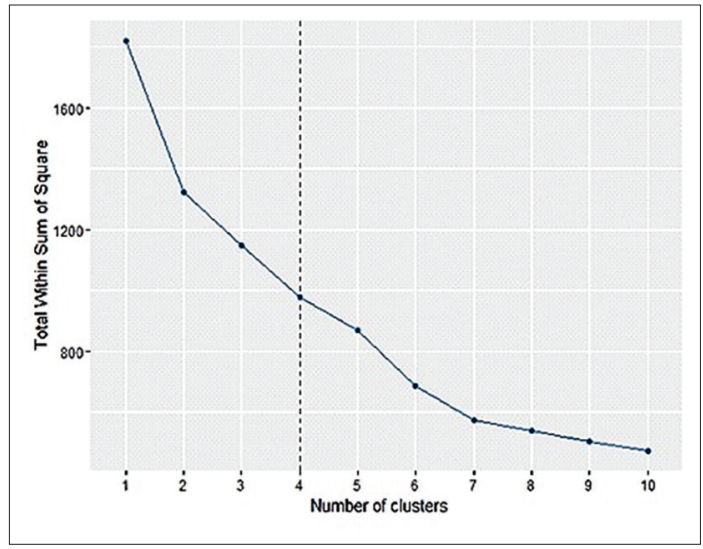

FIGURE 1. Optimal number of clusters

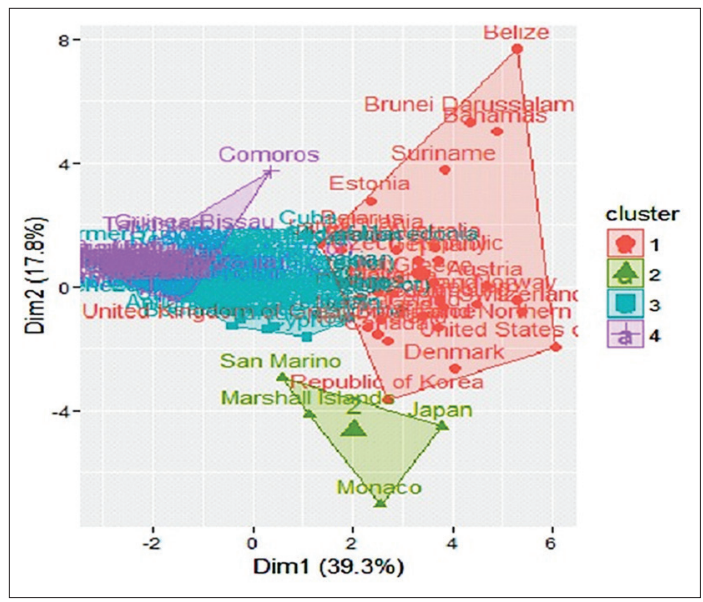

FIGURE 2. Cluster plot

\section{Predictors of the risk of catastrophic expenditure for surgical care}

Graph 1 presents the results of the decision tree generated using Random Forest to find predictors of catastrophic expenditure for surgical care. Number of trees determined as 200 and prediction performance examined using area under the receiver operating characteristic curve indicated good prediction performance (0.82). The decision tree graph shows that surgeon density and medical technology indicators are the most important predictor variables of the risk for catastrophic expenditure for surgical care. Moreover, the decision tree consists of five different groups. First group consists of countries' surgeon density per million population $\leq 0.710$ and LINAC density per million population $>0.075$. The second group composed of countries surgeon density per million population $\leq 0.710$ and LINAC density per million population $\leq 0.075$. The third group consists of surgeon density per million population $>0.710$, LINAC density per million population $>0.090$, and CT density per million population $\leq 2.160$. The fourth group consists of countries surgeon density per million population $>0.710$, LINAC density per million population $>0.090$, and CT density per million population $>2.160$. Finally, the last group consists of countries surgeon density per million population $>0.710$ and LINAC density per million population $\leq 0.090$.

\section{DISCUSSION}

Global volume of surgery increased in recent years. However, the level of development is differed among rich and poor countries. High level of development increased the need for public attention to control costs and to improve the level of surgical services (2). Literature suggests that global medical imaging market grows substantially parallel with the improvement of surgical market (26). The results of this study show that high- and low-middle income countries are in different clusters according to the indicators of surgical care. These results are broadly in line with the literature and suggest that surgical care has been neglected as an integral part of health system development worldwide and considerable differences still exist between countries. Differences between countries emphasize the need for encouraging North American and European aid programs which could play constructive role in helping less developed countries to improve the level of their health-care services (27). 


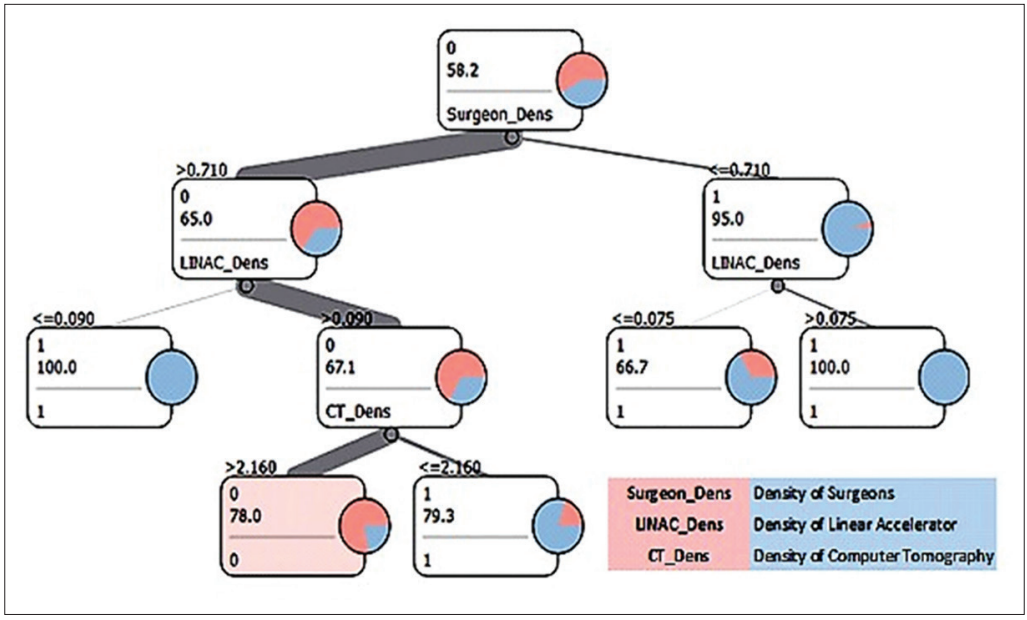

GRAPH 1. Predictors of the risk of catastrophic expenditure for surgical care

From the other perspective, the cost of medical care increases globally and households face with catastrophic expenditure in health care. Catastrophic payments are common in middle-income countries, and most of them are in health transformation process (13). Medical imaging technologies are important part of medical technologies. These can improve patient care because the system can assist healthcare professionals to provide more personalized and effective medical care (28). Moreover, medical imaging technologies are essential parts of surgical care process. Medical imaging is an effective solution to solve ongoing problems in health care. The potential benefits of medical technologies for developing countries are numerous. However, developing countries face with several resource limitations and they are trying to develop modern health-care services while using current medical technologies (27).

Health policymakers need to understand the reasons of the differences between countries according to the surgical care and try to understand whether any country characteristics make people more vulnerable to catastrophic payments. The results of this study highlight that the level of income is the distinguishing feature of the differences between countries according to the surgical care indicators. Furthermore, surgeon density and total density of medical imaging technologies which are LINAC and CT are other predictors of the risk of catastrophic expenditure for surgical care. It has been state that the shortage of qualified health personnel is one of the major treats of health systems worldwide. Studies about future predictions of number of surgeons emphasize that surgeon shortage will continue in the next future (10). On the other hand, LINAC and CT are different kinds of medical imaging technologies which are popular in the diagnosis of surgical care and are found as predictors of the risk of catastrophic expenditure for surgical care in this study. LINAC and CT will continue to be important in the next future in the light of surgical innovation in health (29).

As a result of this study, it is suggested that health policymakers need to focus on the reasons of the differences between countries according to the surgical care indicators. Improving global collaboration between countries according to the indicators of surgical care is a key factor of success $(30,31)$. Furthermore, the current focus in health care shifts from reducing costs to improve quality in health care. These initiatives lead to a reduction of hospital costs and surgical care. Ensuring access to medical technology, improving public funding, and reimbursement systems are other alternative strategies to improve the quality of surgical care in all countries which have different levels of development (5). Overutilization of surgical services is one of the other problems of the health system in general. Resource allocation and social media campaigns will be helpful to create better and transparent global health systems (30). Finally, despite current studies indicate the scarcity of number of surgeons, encouragement 
of surgeons during general surgery training is essential to improve the level surgical care worldwide.

\section{CONCLUSION}

Our study results broadly in line with the literature and emphasizes that the level of income is a determinator of the difference between countries according to the surgical care indicators. What is more our study results call attention to the need for effective planning of human workforce in surgery and medical imaging technologies. We hope that the results of this study will help policymakers in fostering an environment which allows to access current, qualified surgical care.

\section{ACKNOWLEDGMENTS}

This study was supported by a research grant of The Scientific and Technological Research Council of Turkey (TUBITAK) with a grant number 1059B141500020. The sponsor had no role in the study design, collection and analysis of data, the writing of the report, or the submission of the paper for publication.

\section{CONFLICTS OF INTEREST}

The authors declare that they have no conflict of interest.

\section{REFERENCES}

1. Ozgediz D, Roayaie K, Debas H, Schecter W, Farmer D. Surgery in developing countries: Essential training in residency. Arch Surg 2005; 140:795-800.

https://doi.org/10.1001/archsurg.140.8.795.

2. Shrime MG, Dare AJ, Alkire BC, O'Neill K, Meara JG. Catastrophic expenditure to pay for surgery worldwide: A modelling study. Lancet Glob Health 2015;3 Suppl 2:S38-44.

https://doi.org/10.1016/S2214-109X(15)70115-4.

3. Alkire BC, Raykar NP, Shrime MG, Weiser TG, Bickler SW, Rose JA, et al. Global access to surgical care: A modelling study. Lancet Glob Health 2015;3:e316-23.

4. Higgins RM, Frelich MJ, Bosler ME, Gould JC. Cost analysis of robotic versus laparoscopic general surgery procedures. Surg Endosc 2017;31(1):185-92.

https://doi.org/10.1007/s00464-016-4954-2.

5. Hendee WR, Becker GJ, Borgstede JP, Bosma J, Casarella WJ, Erickson $\mathrm{BA}$, et al. Addressing overutilization in medical imaging. Radiology 2010;257(1):240-5.

https://doi.org/10.1148/radiol.10100063.

6. Leitao MM, Narain WR, Boccamazzo D, Sioulas V, Cassella D, Ducie JA, et al. Impact of robotic platforms on surgical approach and costs in the management of morbidly obese patients with newly diagnosed uterine cancer. Ann Surg Oncol 2016;23(7):2192-8.

https://doi.org/10.1245/s10434-015-5062-6.

7. Wyszewianski L. Families with catastrophic health care expenditures. Health Serv Res 1986;21(5):617-34.

8. Cooper RA, Getzen TE, McKee HJ, Laud P. Economic and demographic trends signal an impending physician shortage. Health Aff (Millwood) 2002;21(1):140-54

https://doi.org/10.1377/hlthaff.21.1.140.

9. Ghomrawi HM. Maximizing capacity in times of shortage: A proposal for surgeon volunteerism in the US. Ann Surg 2016;63(6):1073-4

https://doi.org/10.1097/SLA.0000000000001521.

10. Williams TE Jr., Ellison EC. Population analysis predicts a future critical shortage of general surgeons. Surgery 2008;144(4):548-54. https:// doi.org/10.1016/j.surg.2008.05.019.

11. Zapata CJ. Lack of data on standardized metrics for surgical care in a developing country with middle total expenditure on health. Can J Anesth 2016:63(7):894-5

https://doi.org/10.1007/s12630-016-0621-2.

12. Cherkin DC, Deyo RA, Loeser JD, Bush T, Waddell G. An international comparison of back surgery rates. Spine (Phila Pa 1976) 1994;19(11):1201-6. https://doi.org/10.1097/00007632-199405310-00001.

13. Xu K, Evans DB, Kawabata K, Zeramdini R, Klavus J, Murray CJ, et al. Household catastrophic health expenditure: A multicountry analysis. Lancet 2003;362(9378):111-7.

https://doi.org/10.1016/S0140-6736(03)13861-5.

14. Deyo RA, Mirza SK. The case for restraint in spinal surgery: Does quality management have a role to play? Eur Spine J 2009;18 Suppl 3:331-7. https://doi.org/10.1007/s00586-009-0908-x.

15. WHO. WHO Global Health Observatory Data Repository. Geneva: WHO. Available from: http://www.apps.who.int/gho/data/node.main. MEDICALDEVICES?lang=en. [Last accessed on 2016 Sep 26].

16. WHO. WHO The Lancet Global Health, Study Results to Build Global Surgical Specialist Workforce Database by Country. Geneva: WHO; 2015

17. WB The World Bank World Development Indicators. Available from: http:/l www.data.worldbank.org/indicator. [Last accessed on 2016 Sep 20].

18. Fayazbakhsh K, Abedian A, Manshadi BD, Khabbaz RS. Introducing a novel method for materials design using Z-transformation in statistics for normalization of material properties. Metar Design 2009;30:4396-404. https://doi.org/10.1016/j.matdes.2009.04.004.

19. Likas A, Vlassis N, Verbeek JJ. The global k-means clustering algorithm. Pattern Recogn 2003;36:451-61. https://doi.org/10.1016/S0031-3203(02)00060-2.

20. Kanungo T, Mount DM, Netanyahu NS, Piatko CD, Silverman R, Wu AY. An efficient k-means clustering algorithm: Analysis and implementation. IEEE Trans Pattern Anal Mach Intell Anal 2002;24:881-92. https://doi.org/10.1109/TPAMI.2002.1017616.

21. Gersho A, Gray RM. Vector quantization and signal compression. The Springer International Series in Engineering and Computer Science. Boston: Kluwer Academic Publishers, Springer; 1992.

22. Rousseeuw P. Silhouettes: A graphical aid to the interpretation and validation of cluster analysis. J Comput Appl Math 1987;20:53-65. https://doi.org/10.1016/0377-0427(87)90125-7.

23. Muchlinski D, Siroky D, He J, Kocher M. Comparing random forest with logistic regression for predicting class-imbalanced civil war onset data. Polit Anal 2016;24(1):87-103.

https://doi.org/10.1093/pan/mpv024.

24. Liaw $A$, Wiener M. Classification and regression by randomforest. $R$ News 2002;2:18-22 
25. Chattamvelli R. Data Mining Methods. Oxford UK: Alpha Science International Ltd.; 2009.

26. James AP, Dasarathy BV. Medical image fusion: A survey of the state of the art. Inf Fusion 2014;19:4-11.

https://doi.org/10.1016/j.inffus.2013.12.002.

27. Banta HD. Medical technology and developing countries: The case of Brazil. Int J Health Serv 1986;16:363-73.

https://doi.org/10.2190/7H41-XEEB-AQYY-0CN6.

28. Mohd-Nor R. Medical imaging trends and implementation: Issues and challenges for developing countries J Health Inf Dev Countries 2011;5:89-98.
29. Rotter N, Schmitz B, Sommer F, Röhrer S, Schuler PJ, Bischof F, et al. First use of flat-panel computed tomography during cochlear implant surgery: Perspectives for the use of advanced therapies in cochlear implantation. HNO 2017;65(1):61-5.

https://doi.org/10.1007/s00106-016-0213-z.

30. Ryden L, Stokoe G, Breithardt G, Lindemans F, Potgieter A. Patient access to medical technology across Europe. Eur Heart J 2004;25(7):611-6. https://doi.org/10.1016/j.ehj.2004.02.015.

31. Picano E. Sustainability of medical imaging. BMJ 2004;328(7439):578-80. https://doi.org/10.1136/bmj.328.7439.578. 